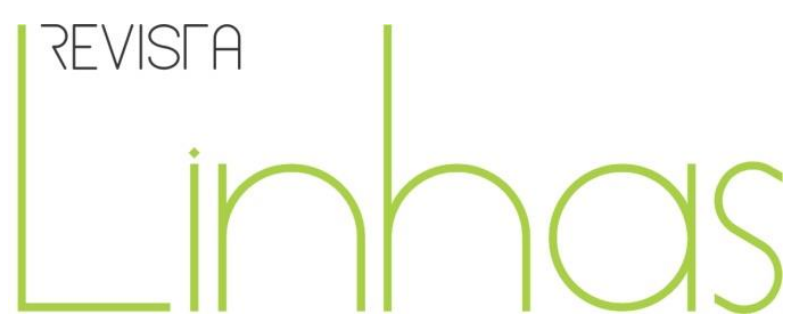

\title{
Resenha do livro "Mezzi di educazione di massa. Saggi di storia della cultura materiale della scuola tra XIX e XX secolo"
}

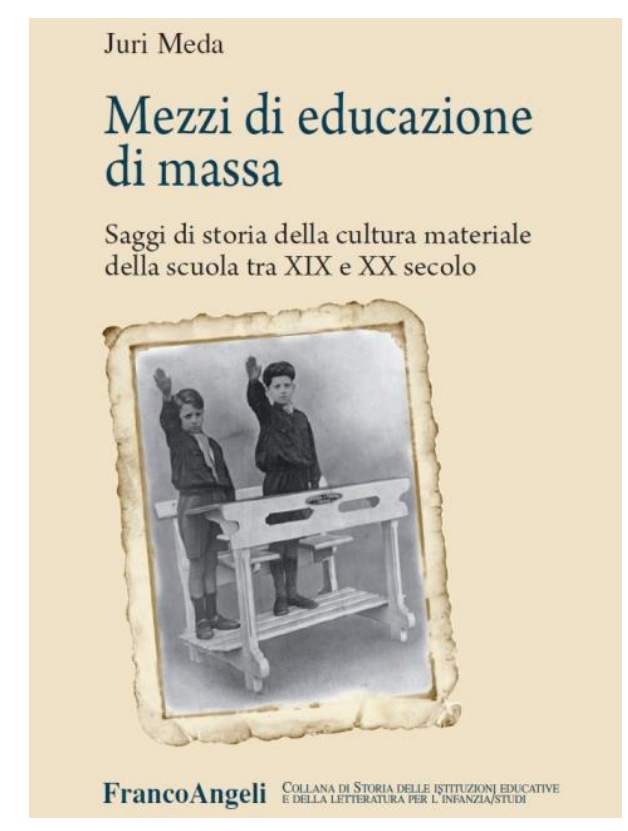

MEDA, Juri. Mezzi di educazione di massa. Saggi di storia della cultura materiale della scuola tra XIX e XX secolo. Milano: Franco Angeli, 2016. 226 p.

\author{
Vera Lucia Gaspar da Silva \\ Universidade do Estado de Santa Catarina - UDESC - Brasil \\ vera.gaspar.udesc@gmail.com \\ Gizele de Souza \\ Universidade Federal do Paraná - UFPR - Brasil \\ gizelesouza@uol.com.br
}

\begin{abstract}
Para citar esta resenha:
GASPAR da SILVA, Vera Lucia; SOUZA, Gizele de. Resenha do livro "Mezzi di educazione di massa. Saggi di storia della cultura materiale della scuola tra XIX e XX secolo". Revista Linhas. Florianópolis, v. 18, n. 37, p. 318-322, maio/ago. 2017.
\end{abstract}

DOI: $10.5965 / 1984723818372017318$

http://dx.doi.org/10.5965/1984723818372017318 
O livro "Mezzi di educazione di massa: Saggi di storia della cultura materiale della scuola tra XIX e XX secolo", de autoria do italiano Juri Meda, integra a Coleção de História das Instituições Educativas e da Literatura para a Infância, coordenada por Anna Ascenzi e Dorena Caroli (Università degli Studi di Macerata, Italy). Tal coleção se ocupa da publicação científica dirigida tanto a um público especializado quanto a estudantes, professores e amantes dos estudos histórico-educativos e de literatura para a infância. A edição italiana traz na capa a imagem de dois alunos uniformizados em uma carteira escolar de dois lugares - do Tipo A - fabricada por Ditta Flecchia \& Torchio, retirada do Catalogo degli arredi scolastici, 1928 (Coleção privada do autor).

Lançada em 2016, a obra conta ao menos com duas importantes resenhas publicadas em periódico italiano e espanhol. A primeira, de autoria de Vera Zamagni, uma historiadora econômica italiana, integra a seção Notiziario bibliografico da Revista “Ricerche Storiche” (Anno XLVI - Número 3 / Settembre-Dicembre 2016, Pisa/Italia: Pacini Editore pp. 158-159). A segunda, de autoria do espanhol Antonio Viñao, encontra-se publicada na Revista Historia y Memoria de la Educación 6, de 2017 (pp. 537-543), periódico da Sociedade Espanhola de História da Educação.

Neste estudo, a escola é assumida como instrumento gerador da identidade nacional e partícipe da construção do Estado-Nação, mas, num espectro político que agrega formas de articulação ainda não tão comuns nas narrativas historiográficas da educação. O autor tece as análises tendo como eixo central a dimensão econômica da escolarização de massas, a qual tem sido indicada em outros estudos sem ganhar a centralidade que vemos na presente obra. Juri Meda constrói, com base em farta documentação, a tese de que o projeto de escolarização de massas necessitou de uma articulação fecunda com setores empresariais, que assumiram a tarefa de produzir o aparato material que sustentaria a edificação de tal projeto de escolarização da infância.

O livro está organizado com Introdução, cinco capítulos, apêndices e índice de nomes.

$\mathrm{Na}$ introdução, o autor se dedica a situar o tema, apontando estudos que ajudam a delinear as escolhas, autores italianos e estrangeiros e as principais formas de abordar a expansão da escola de massa que vem recebendo a atenção da comunidade de historiadores da educação. Assinala que a efetivação do princípio da obrigatoriedade 
escolar, na Itália, trouxe um novo potente mercado - o escolar - inicialmente com o crescente interesse dos editores, tipógrafos, legisladores e, sucessivamente, com uma ampliação para artesãos e outros empreendedores de material escolar. Argumenta ainda que com este fenômeno da escolarização de massas e com atuação do regime fascista, deu-se impulso a uma "estandardização dos materiais didáticos e dos materiais escolares" (p. 11). Outro aspecto interessante sublinhado pelo autor é que em meio a este processo já mencionado, se alteram papéis de atores do ambiente educativo como, por exemplo, o do professor que se transforma de "artesão do saber" - expressão emprestada do pesquisador Benito Escolano - ao cliente de empresas industriais. Diante deste contexto, o historiador Juri Meda avalia que não se pode se eximir do estudo dos processos econômicos articulados ao desenvolvimento da escolarização de massa e da consequente transformação da manufatura escolar em indústria escolar.

O Capítulo 1, subdividido em cinco itens, é dedicado à localização da reflexão italiana e internacional que se ocupa da cultura material escolar. Nele, o autor intenta identificar distâncias e vizinhanças entre formas de reflexão sobre a temática, que têm sido cunhadas na Itália e fora dela e utiliza como fio condutor a história da indústria editorial do livro escolar. Para fazê-lo, entrecruza dados sobre a indústria editorial e a produção de cadernos. O último item deste capítulo advoga a potencialidade de estudos que tomam a cultura material escolar como objeto de análise e categoria interpretativa para se compreender a difusão da escola de massas.

No Capítulo 2, o objeto que conduz as reflexões é o banco escolar, analisado como artefato organizador do espaço, atravessado por aspectos higiênicos entrecruzados por interesses comerciais. A história do mobiliário escolar é explorada como indústria em expansão que acompanha o aumento da população escolar e a regulamentação moral que atinge com força este espaço. Questões higiênicas e de ordem moral se mesclam na conformação de um corpo escolar pedagogizado e patologizado. Outro aspecto tratado neste capítulo relaciona a especificação formal do banco escolar com a organização da produção em larga escala deste artefato que a indústria iria incorporar comum um promissor segmento. Mas, esta organização da sala de aula não é unânime e críticas ao formato linear que induziriam a filas são trazidas ao texto, particularmente pelos 
argumentos registrados por Maria Montessori, que apostaria em outro tipo de mobiliário e configuração do espaço.

No Capítulo 3, o objeto em cena é o caderno escolar, cuja análise é atravessada pelas exigências didáticas e interesses comerciais. Aqui, o autor explora o caderno como objeto material, como produto industrial que acompanha e se alimenta da expansão da escolarização, em meio a contendas entre o Estado, a indústria e o comércio, este último representado pelas papelarias.

No Capítulo 4, o "diário escolar” (entre nós mais conhecido como agenda escolar), importante dispositivo de comunicação entre a escola e a família, é detidamente explorado. Concentrando as análises no período que vai de 1930 a 1945, Juri Meda explora este artefato como canal de infiltração ideológica do regime conduzido por Mussolini para alcançar as famílias dos escolares.

Por fim, no Capítulo 5, o autor se dedica a fazer uma reflexão que agrega aspectos abordados nos capítulos anteriores e reafirma sua aposta de investigação e análise da constituição da escola de massas, tendo por eixo a indústria que se configura como importante braço a dar-lhe forma.

Nos apêndices, o leitor entra em contato com um conjunto de informações sobre marcas, indústrias e estabelecimentos dedicados à comercialização de artefatos escolares, bem como, de fabricantes e comerciantes.

\section{Sobre o autor}

Juri Meda é pesquisador do Departamento de Educação, de Cultura e Turismo da Universidade de Macerata, onde ensina História de escolas e instituições de ensino. É membro de comitês de revistas científicas italianas e estrangeiras. Tem produzido artigos e ensaios com regularidade, dedicando-se com afinco aos estudos da história da cultura material da instituição escolar. Sua produção está disponível tanto na Itália como em outros países. No Brasil, destacamos os artigos "Os desenhos infantis como fontes históricas: perspectivas heurísticas e questões metodológicas", publicado na Revista Brasileira de História da Educação (v. 14, n. 3 (36), pp. 151-177, set./dez. 2014) e "A 'história 
material da escola' como fator de desenvolvimento da pesquisa histórico educativa na Itália", publicado na Revista Linhas (v. 16, n. 30, p. 07-28, jan./abr. 2015).

Recebido em: 13/01/2017

Aprovado em: 27/01/2017

Universidade do Estado de Santa Catarina - UDESC Programa de Pós-Graduação em Educação - PPGE Revista Linhas Volume 18 - Número 37 - Ano 2017 revistalinhas@gmail.com 